\title{
Chief Complaints and Diagnosis of Patients Visited by Caravan Physicians During Hajj 2010
}

\author{
Sayyed Ali Marashi ${ }^{1}$; Hojjatollah Rusta ${ }^{2}$; Aminreza Tabatabaei ${ }^{3,{ }^{*}}$ \\ ${ }_{1}^{1}$ Hajj and Pilgrimage Medical Center, Tehran, IR Iran \\ ${ }^{2}$ Department of Cardiology, Shiraz University of Medical Sciences, Shiraz IR Iran \\ ${ }^{3}$ Department of Education and Research, Hajj and Pilgrimage Medical Center, Tehran, IR Iran \\ *Corresponding Author: Aminreza Tabatabaei, Department of Education and Research, Hajj and Pilgrimage Medical Center, Tehran, IR Iran. Tel: +98-2186744114, E-mail: art@hmc.ir
}

Received: June 11, 2013; Revised: February 8, 2014; Accepted: March 11, 2014

\begin{abstract}
Background:The primary data on the patient's status are articulated by the patient and consist of conditions that force the patient to seek treatment. Such data helps the physician effectively to make an appropriate list of differential diagnoses to establish a treatment protocol. Objectives: The objective of this study was to review the frequency of patients' chief complaints in Hajj to plan and develop medical protocols for expected problems in Hajj.

Patients and Methods: In this short-term past-oriented study, all medical files of the Hajj pilgrims were reviewed and all data regarding the diagnoses were extracted.

Results: In general, medical data of 107074 cases had been registered in this software. Cough with the frequency of 24083 (22.45\%) was the most frequent complaints of the patients. Respiratory tract infections diseases with 66197 persons (61.82\%) were the most frequently diagnosed diseases in times of annual Hajj of 2010.

Conclusions: Respiratory disease, musculoskeletal pain, headache, and digestion problems were among the most important reasons of patients' referral to physicians in times of Hajj. The mentioned complications could be prevented through correct trainings and conforming to health recommendations in times of Hajj.
\end{abstract}

Keywords: Common Cold; Respiratory Disease; Training; Outbreak

\section{Background}

Hajj is one of the main rituals of Islam, a religious duty that must be performed by each healthy and able-bodied Muslim who can afford to do it. Persons must be in a good health status to benefit from the pilgrimage time. The population of Mecca and Medina increases from 200000 to over 3 million in times of annual Hajj (1). Such increase introduces various challenges such as provision of sufficient food and water, supplying hygienic accommodation in Mecca, Mina, and Arafat where the pilgrims must perform part of their rituals. From Iran, about 100000 pilgrims in caravans of 100 and 200 pilgrims are transferred to Saudi Arabia during Hajj season (1).

Due to the health and hygienic issues during this 35-day event and to remain immune from medical interventions, Iranian hajj policymakers has categorized health services during Hajj for the sake of providing more accommodation and welfare for Iranian pilgrims (2). In the first level, there is a general physician in each Caravan who accompanies the pilgrims in the caravan and is informed of the medical conditions of his assigned pilgrims. If a pilgrim needs specialized or complementary medical services, he/she would be transferred to the Iranian Red Crescent Hospital in Mecca and Medina after filling the hospital reference form by the caravan physician (3).
Caravan physician is in charge of pilgrims' health and he is the highly referred person. This is why a review on the degree of disease outbreak in times of Hajj can be regarded as an effective help in designing Hajj health plan and enables authorities to develop a right plan to protect the pilgrims ` health and to train them in managing the most prevalent diseases in Hajj. Generally, the first data obtained from the patients includes symptoms and problems articulated by them (4), which are the main causes of seeking treatment.

\section{Objectives}

The objective of this study was to review the frequency of pilgrim's chief complaints in Hajj to plan and develop medical protocols in Hajj.

\section{Patients and Methods}

In this retrospective cross-sectional study, which was conducted in 2010, the physictional system of medical reports on patient by the physicians was reviewed. This system provided the medical screening of all pilgrims' specifications before travel in form of software for caravan physicians. In the course of travel, all data regarding the prescribed medicines, patients' chief complaint, and

Copyright (C) 2014, Iranian Red Crescent Medical Journal. This is an open-access article distributed under the terms of the Creative Commons Attribution-NonCommercial 4.0 International License (http://creativecommons.org/licenses/by-nc/4.0/) which permits copy and redistribute the material just in noncommercial usages, provided the original work is properly cited. 
diagnosis would be registered in this software. Such inputs were delivered to hospital information system and would be extracted and reviewed accordingly. Examined variables included patient's complaints and their clinical diagnosis. There were any executive restrictions except for the change of the caravan's physicians every year. All Iranian pilgrims' data in software were selected and enrolled in this study by census sampling method and analyzed. Non-Iranian patients were excluded. The study was ethically approved by the Health Research Ethics Committee of the Hajj and Pilgrimage Center. Confidentiality of names and data of all the subjects was observed.

After completing checklists, SPSS software 15 (SPSS, Inc., Chicago, IL) was used for analysis of data and variables were described using frequencies and percentages or means and standard deviations.

\section{Results}

In general, medical d107074 cases was registered in this software with 70754 persons (66.08\%) in Mecca, 31083 (29.03\%) in Medina, 1874 (1.75\%) in Arafat, and 3363 (3.14\%) in Mena. The mean age of patients was $54.71 \pm 21.84$ years (range, 21 to 98 ).

Figure 1 shows major complains that had led to patients referral to caravan physician. Cough was the most common major complaints seen in 24083 persons (22.45\%). Other frequent complaints were consecutively coryza, dysphagia, control of underlying disease, musculoskeletal pain, fever, headache, and low back pain.

Figure 2 shows that the respiratory tract infections, with 66197 affected persons (61.82\%), were the most diagnosed diseases in times of annual Hajj of 2010. Other frequent diagnoses were consecutively muscular spasm, allergy, purulent pharyngitis, acute bronchitis, gastritis, pneumonia, laryngitis, and trauma.

Regarding prescribed medicines, 92967 cases had received medicine. The most prescribed medicine was adult cold tablets with 12280 cases (13.21\%) followed by amoxicillin (5942 cases [6.93\%]) and diphenhydramine $\operatorname{syrup}(5867$ cases $[6.31 \%])$.

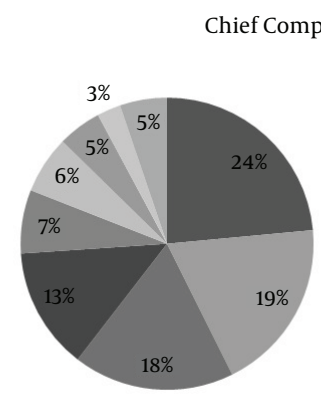

$$
\begin{aligned}
& \text { - Cough } \\
& \text { m runny nose or nasal congestion } \\
& \text { congestion } \\
& \text { - Throat irritation } \\
& \text { - Control of underiying disease } \\
& \text { - Limb pain } \\
& \text { - Fever \&chills }
\end{aligned}
$$

Figure 1. Frequency of Pilgrim's Chief Complains in Hajj 2010

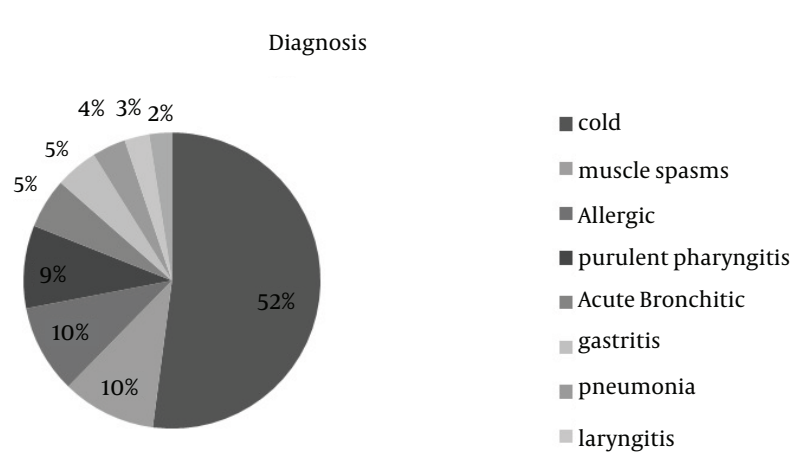

Figure 2. Frequency of Pilgrim's Diagnoses in Hajj 2010

\section{Discussion}

The present study showed that the most frequent diagnoses in pilgrims of Hajj 2010 were consecutively respiratory tract infection (54.02\%), muscular spasm, gastrointestinal, and skin diseases.

Prolonged cough was reported in a large proportion of two million pilgrims who participate in hajj in Saudi Arabia. In hajj pilgrimage season, people gather in a small confined area in Mecca. Respiratory tract infection is the most common disease transmitted during this period (2). Other studies showed the high rate of influenza virus infection outbreaks among pilgrims returned from Mecca. It indicates the necessity of developing an international strategy to reduce the risk of epidemics (5). In addition to highlighting prevention, such strategy must be able to made the immediate diagnosis and provide treatment for infected cases. It should be noted that no coordinated plan has been implemented so far. The shift in time of Hajj to winter form year 2000, has led to an increase in the outbreak of respiratory tract infections caused by influenza and other common viruses (6).

In spite of excellent efforts by Health Ministry of Saudi Arabia in provision of hygienic and medical facilities, such huge gathering is an appropriate ground for the outbreak of diseases. In time of hajj, as the largest annual gathering of the world, many people are in close contact with one another, which increases the probability of the outbreak of common as well as new respiratory tract infections. The probability of infection outbreak is higher in crowded places. Recommendation Saudi Arabia Ministry of Health to pilgrims, especially those with underlying diseases (elderly or people with chronic diseases, heart failure, etc.), is vaccination against influenza before trip. Nonetheless, due to high rate of influenza attacks in winter and cold months, influenza vaccination before travel to the pilgrims is recommended to all age groups. However, an independent study on the efficacy of influenza vaccine during the Hajj is necessary (5). 
According to other results of our study, with high frequency of common colds, higher frequency of prescribing cold suppressing drugs seems logical. Frequent administration of non-steroidal anti-inflammatory drugs and antibiotics seems to be more than usual. Therefore, revising in prescription of medications by caravan physicians is essential because this problem increases the risk of adverse effects of steroids and antibiotics as well as microbial resistance. This study is the first study on the prevalence of disease in Hajj with a large of samples size. Nevertheless, this study has some limitations. We have not data for analyzed association between demographic variables and kind of disease because our software recorded demographic data with complaints and diagnosis.

\section{Acknowledgements}

The authors would like to acknowledge the Hajj and Pilgrimage Medical Center.

\section{Authors' Contributions}

Study concept and design: Sayyed Ali Marashi and Aminreza Tabatabaei; acquisition of data: Hojjatollah Rusta; analysis and interpretation of data: Aminreza Tabatabaei; drafting of the manuscript: Aminreza Tabatabaei; critical revision of the manuscript for important intellectual content: Hojjatollah Rusta; statistical analysis: Aminreza Tabatabaei; administrative, technical, and material sup- port: Sayyed Ali Marashi: and study supervision: Aminreza Tabatabaei.

\section{Financial Disclosure}

The funding organizations were public institutions and had no role in the design and conduct of the study, collection, management, and analysis of the data, or preparation, review, and approval of the manuscript.

\section{Funding/Support}

This study was supported by Hajj and Pilgrimage Medical Center.

\section{References}

1. Mohamed MN. Hajj to Umrah: From A to Z.: Amana Publications; 1996.

2. Al-Harthi AS, Al-Harbi M. Accidental injuries during muslim pilgrimage. Saudi Med J. 2001;22(6):523-5.

3. Riaz A, Dandehbor V, editors. Assessing the challenges in health care domain from central medical organization of hajj and pilgrimage directors' perspective in hajj 2011. .; 1th International Medical Congress on Hajj\& Pilgrimage.; September 1st, 2012; Tehran, Iran. p. 56.

4. Dandehbor V, Heidari S, Biranvand B, editors. Assessment of challenges and problems in health care from caravan managers' point of view.; Hajj and Pilgrimage Medical Congress.; 2012; p. 45.

5. Riaz A, Mortazavi M, editors. Prevalence of underlying diseases in Tamattu, 2011.; Medical Congress in Hajj \& Pilgrimage.; 2011; Tehran. p. 12.

6. Tabatabai A, Shamspour N, editors. Most mental illnesses cause patients to refer the Iranian pilgrims before in Hajj season.; Medical Congress in Hajj and Pilgrimage.; 2011; Tehran. p. 47. 